\title{
Role of the team physiotherapist in rugby union football
}

\author{
D.A. McLean, BA, MCSP, CertEd \\ Senior Lecturer, The Queen's College, Glasgow G3 6LP, UK
}

\begin{abstract}
The team physiotherapist plays an important role in rugby union football. Traditionally, this is seen as injury care and rehabilitation, but increasingly the role focuses on injury prevention. The author discusses these aspects with reference to statistics from recent Scottish international tours.
\end{abstract}

Keywords: Rugby union football, physiotherapy, injury prevention

\section{Introduction}

In soccer and rugby the popular image of the team physiotherapist is the man on match day with a black bag and the magic sponge. Certainly it is a role commonly undertaken, yet it is the least important. Central to the job is injury care and rehabilitation. The most important role of the team physiotherapist is injury prevention. This can only be achieved if the physiotherapist is part of a support team consisting of manager/coach, doctor and administrator. To ensure that all members of the support team not only believe in injury prevention but will act accordingly is a major challenge.

Over the last 10 years I have been associated as a team physiotherapist with the sport of rugby union.

\section{Field of play}

A change in the rules allows players to receive attention for an injury while play continues. This was initiated to reduce the number of stoppages. It was felt that players feigned injury to gain a tactical advantage. The fact that this occurred is supported by the reduction in stoppages since the new law was implemented in 1988.

- The feigning of injury and the sudden complete recovery makes the spectator question in every case how it is possible for players to be completely incapacitated one minute yet able to play normally the next. Many injuries in contact sport are totally disabling for approximately two minutes; being winded, being kicked on the inside of the knee, or the hand being numbed when stood on. The effect can be more long lasting and the fact that the player is soon

Address for correspondence: D.A. McLean, Queen's College, 1 Park Drive, Glasgow G3 6LP, UK.

(C) 1990 Butterworth \& Co (Publishers) Ltd

0306-3674/90/010019-06 able to function normally is testimony to the stoical nature of the determined competitor.

The decision which has to be taken when a player is injured during the game is whether or not full function can be achieved. If not, then the player should leave the field of play. The steps in the process of examination are exactly the same as those in a clinic. The only difference is that it has to be done in about one minute.

From the bench at the side of the pitch, observation of the mechanism of injury is often impossible. Thus the first questions are 'What happened?' and 'Where does it hurt?'. The next question asks the player to move the injured part. Depending on the responses elicited, tests of joint stability are performed. If these are normal, the player must then demonstrate full active range and full isometric muscle strength. The time which this process takes allows the player to overcome the shock of trauma along with the fear of severe injury and its consequences. At this stage, the player may request cold or an embrocation to be applied to the skin as a counter-irritant. The next two minutes of activity in the game is the final test of functional ability. All of the above assumes the injury to be to the limbs, which it is in the majority of cases.

Head 'knocks' require a slightly different approach. When the player is lying motionless, the patency of the airway and normal function of the cardiorespiratory systems are paramount. More often, if the player has lost consciousness, he is recovering by the time the physiotherapist reaches him. The first questions test understanding of commands and memory. Coordination of eye movements may be checked. The player may complain of altered vision. The easiest gross test of the nervous system, and the test which is most often positive, is inability to balance. The player may either stagger when getting to his feet, or will be unable to balance unaided while standing on one leg.

Irrespective of the injury, where there is any uncertainty about a player's ability to continue, he should be removed from the field of play until he is able to demonstrate his fitness. The role of the medical adviser is very important at this stage. This regime is obviously of benefit to the player and it is better for the team since a player whose fitness is in question will produce misunderstanding and errors. The introduction of replacements in rugby union has helped to avoid players continuing to play when unfit to do so. 


\section{Preparation for the game in the changing room}

The structure of the hour before kick-off is very much in the hands of the coach and the team captain. There are a great variety of activities carried out by groups and individuals during that hour. If there are aspects of the preparation which appear to be misdirected then through informal conversation the activity can be analysed. If it is judged to be inappropriate, changes can be introduced. An example is the avoidance of over vigorous warm-ups started too early in hot humid changing rooms. This reduces energy stores and causes unnecessary fluid loss. Moderate fluid intake is encouraged in the changing room. Wherever possible, appropriate indoor or outdoor warm-up facilities should be provided and used. It is sensible for teams to use the field of play. Warm-ups should include skills and activities which are part of the game ${ }^{1}$.

The same applies to individual players. While it is accepted that much of the activity is for psychological effect, if activities are noted to be dangerous or negative in effect then, through discussion, the player's activities may be modified. The unexpected can be avoided wherever possible by getting to know players. However, the levels of stress just before kickoff can lead to the most unusual requests. Experience is the best guide to response. Players may request joints to be manipulated. Even if the player is well known to the physiotherapist, this is a difficult request to respond to and would demand careful review to identify if in fact manipulation was actually needed.

Many players apply strapping and do so to an appropriate standard. However, there are examples when strapping could be applied more efficiently. Player education is required. The same applies to active and passive warm-ups. The massage prior to the game does not replace an active warm-up. However, players often seek the sanctuary of the couch where they can lie quietly and, with the help of slow deep massage, try to manage their high levels of stress. Some players use the firm physical contact of massage as the first step in preparation for physical contact.

Order, organization and forward planning avoids complications and worrying distractions. Every member of the support team must play his part to achieve this.

\section{Preparation before the game}

As much as possible is done before arriving at the stadium. Adhesive strapping is used for those with previous history of inversion injury ${ }^{2}$ or talar instability $^{3}$. Strapping can also be used to control hyperextension of knee or elbow ${ }^{4}$. Protection may be needed for an acromioclavicular joint which is still locally tender following subluxation. Padding of feet or boots is frequently required for bruising of the dorsum of the foot which inhibits kicking, or blisters which inhibit running. When grounds are hard, bony points may suffer direct trauma. This causes longlasting pain on direct contact and so benefits from protection. Figure 1 shows one example of the use of chiropody felt positioned to protect a recent cut just above the eyebrow. Secured in the substance of the felt is a piece of thermoplastic. Make-up was used to make the pad skin coloured to avoid attracting attention. It is important that examples such as these are skilfully applied and the player has time to test them before the game so that adjustments can be made. Better still, the effect of padding and strapping can be tried out on the final practice session before the match.

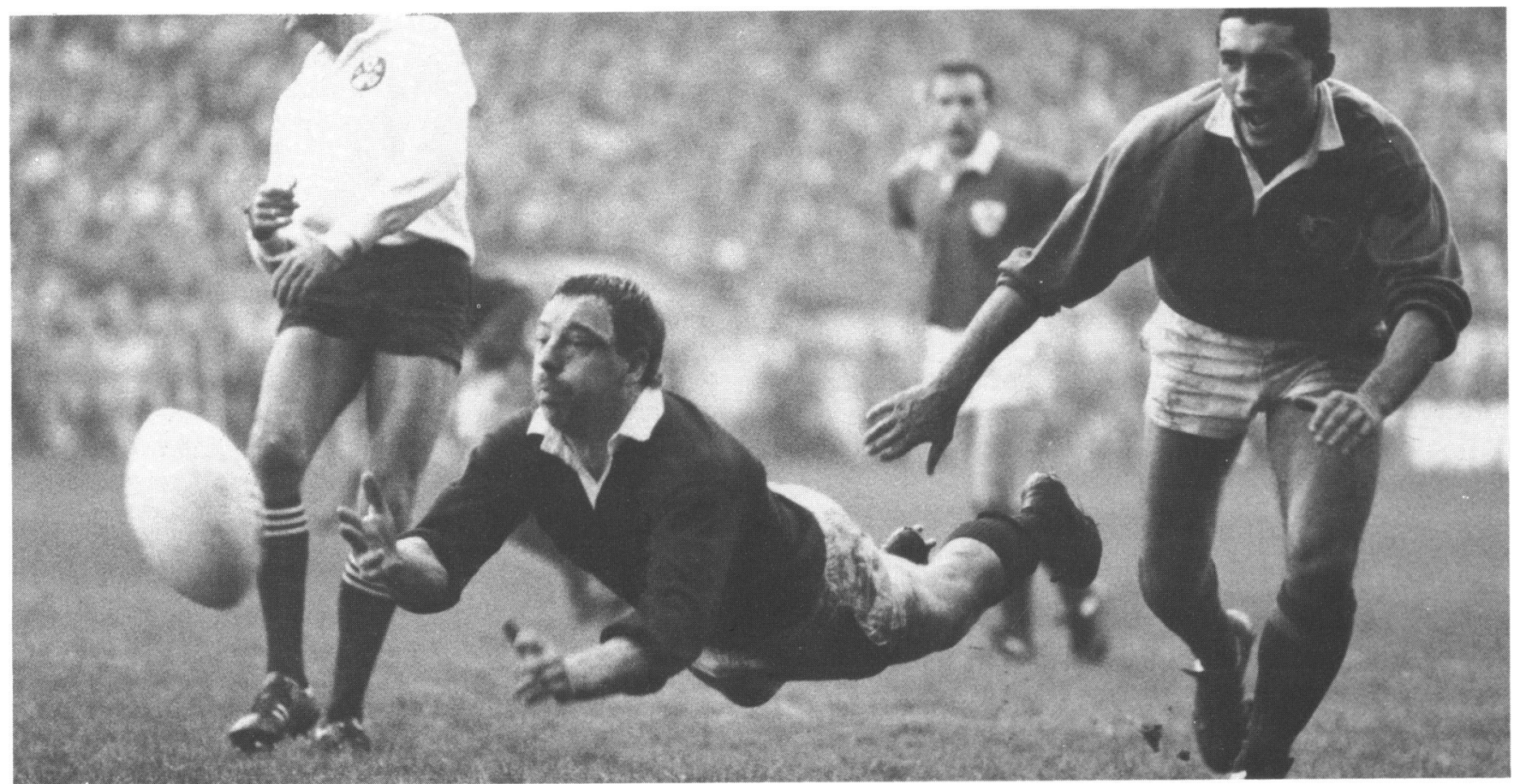

Figure 1. Chiropody felt used to protect an injury above the eyebrow. (Courtesy of the Glasgow Herald). 
It is widely recognized that in soccer and rugby union some players are not 100 per cent fit when they take the field. Seasons are long and punishing and players accumulate problems. In training, contact occurs up to two days before the match and injuries occur or past injuries can be aggravated. Immediate treatment to reduce the amount of tissue reaction is essential ${ }^{5}$. Muscle soreness and tightness is common and, because this appears to predispose to muscle disruption, everything possible must be done to reduce these. Gentle activity, heat and massage are used $^{6}$.

\section{Fitness to play following injury}

Decisions about fitness to play can be very difficult to make. In rugby union the laws of the game state that it is the player who declares himself fit to play. The player's view is important. However, it is hoped that he will listen to advice. The longer the back-up team and the players have been working together then the more likely it is that there will be mutual trust. Decisions have to be made about injuries which occur in the two weeks prior to a match. This amount of time away from full training causes a small physiological decrement. In fact, in the middle of a season this length of break may have psychological benefits. In these cases the problem remains to predict the rate of recovery since to rule the player out unnecessarily would be wrong, yet to leave the decision too late may disrupt team preparation. One reason for the difficulty in predicting rate of recovery is that the degree of disruption of soft tissue injuries cannot be measured directly. Five general guidelines are included to help judge prognosis.

\section{- Onset}

When sudden pain is felt during running, the severity of disruption is likely to be greater than when the onset of pain is delayed until the next day. Both cases allow a clearer judgement to be made about severity than when the onset is spread over several days or weeks.

- Degree of function at the time of injury

Because of pain, fear and anxiety the picture is not clear unless of course there is complete rupture, dislocation or fracture.

- Joint range and muscle strength at 24-28h post injury A better judgement of severity can be made at this stage. However, inhibition due to pain may still cloud the issue.

- Rate of improvement within the first four days

Force production, rate of force production, and percentage of top running pace achieved, will help judgement of the rate of recovery over the next week or two. This is illustrated by comparison of two examples in Table 1.

- Previous history of a similar injury

If comparison can be made with a previous injury suffered by the player, then the time to recovery of that injury is a useful guide.

The person in overall charge of team selection will set a deadline by which time the player has to demonstrate his fitness.
Table 1. Partial tear of hamstrings. Two subject comparison of maximum voluntary contraction (MVC) and return to play

\begin{tabular}{ccccc}
\hline Days post injury & Day 3 & Day 10 & Day 21 & Day 35 \\
\hline Subject 1 & $60 \%$ MVC & - & - & Play \\
Subject 2 & $90 \%$ MVC & Play & Play & Play \\
\hline
\end{tabular}

To demonstrate fitness, all positive tests originally carried out on the examination couch should now be negative. All elements of function can be tested in the final squad session before the game, but it is possible for players to hide any remaining dysfuriction if this is the only method of testing. Full speed, acceleration, and ability to change direction should be carried out in competition with other players and comparisons made. Comparisons can also be made if previous measurements for the same tests have been recorded.

In the real world, many more aspects than physical fitness are considered before a final decision is reached. Relevant factors include the quality of player resource, the relative importance of the game and those which follow, the time in the season or the tour, the experience of the player and the stage of the player's career.

\section{Rehabilitation}

In rehabilitation of musculoskeletal injuries the time to full recovery may be split into three phases. The first phase coincides with the acute stage which may span approximately two to five days. The second phase is one of restricted physical activity which may span three days to six weeks or even longer. The final phase is participation in the game at a level below the player's recognized level of ability.

In phase one, the objective is to prevent or reduce secondary cell death ${ }^{7}$ and thus the accompanying delay of resolution. This is achieved by applying the principles of acute injury care ${ }^{5}$.

In phase two, restricted activity is carried out within the limits of pain. Initially, the aim is to stimulate resolution of the inflammatory process ${ }^{8}$ as well as good quality of repair. Re-education of use is included. The major components are balance, equality of function between right and left, and eccentric muscle control. Within this phase, the objective of restricted activity gradually moves towards retraining to achieve physiological fitness and tissue fitness; that is tensile strength and elasticity of connective tissue. The latter part of this phase may involve certain units of training done with the squad.

Phase three allows the player to test his fitness and skill levels where the added pressure of winning is less and the quality of opposition less severe. It provides time for the player to regain confidence.

Each phase is important, but the phase of greatest effect is the second phase because it is here that the foundations are laid for prevention of recurrence of injury. 
The content, structure and progression of phase two are difficult to judge because there is no biomechanical model on which to base a retraining programme other than the principle that activity stimulates repair ${ }^{9}$. Studies of tendon healing, ligament healing and wound healing offer guidelines, but the large majority of sports injuries are not total ruptures so these time scales do not necessarily apply. If one adds to this conditions such as tendinitis and focal degeneration in tendons, then exact predictions of the timing and vigour of reloading of ligament and tendon are impossible.

Muscular injuries pose similar problems. Since the majority of muscle injuries in sport are partial tears, a most relevant study by Nikolaou ${ }^{10}$ investigated the effect on rabbit muscle when strained to 80 per cent of failure. The result was tearing of muscle fibres near the distal musculotendinous junction. The ability of the muscle to generate force was maximally reduced at $24 \mathrm{~h}$ recovering to 92 per cent in seven days when scarring and fibrosis was evident. The experimental method made it clear that the cause of the force reduction was intrinsic to the muscle. It must be remembered that healing in rabbits may be quicker than in humans. Clinical evidence would suggest that the average recovery to full function for hamstring strains is 14 days $^{11}$, yet in 14 days fibrous repair has regained only 25 per cent of its tensile strength ${ }^{12}$. This apparently conflicting evidence illustrates the dilemma when dealing with the musculotendinous unit. Resolution of arthropathies is just as difficult to gauge $^{13}$

In view of these limitations, the foundations on which to base phase two of rehabilitation are very insecure. Guidelines, therefore, are general but are necessary to enable a way forward to be identified. In addition to the five guidelines included in the section above, a further four are listed to help identify the appropriate type of activity and work-load.

- Total time of inactivity or unstructured activity since the injury

A judgement on how much fitness has been lost ${ }^{14}$ and whether or not the activity will have allowed healing or prevented healing can be made.

- Intensity and volume of work (load degree) prior to injury

This aids in the identification of the initial load degree, taking into account the time of any inactivity. This may have a bearing on the cause of the injury.

- Dependency of recurrence on intensity or volume This determines which of the two should be avoided in the early stages of recovery.

- Components of performance to be maintained or improved

There may be objectives of conditioning, skill development or tactical awareness which can be included which have no detrimental effect on the injury. Indeed, they may have a positive effect on the quality of repair.

Wherever possible the activity chosen to aid recovery should be structured in such a way to produce a training effect for components of fitness required by the sport ${ }^{15}$.

The following is an example of one unit of work included in phase two to illustrate the use of the last four guidelines. A player suffered a partial tear of the adductor longus muscle when sprinting from a standing start. Ten days later, hip abduction was full and painless as was manually resisted hip adduction, flexion and medial rotation. He was able to reach 50 per cent of his top running pace before pain was experienced. Previous to the injury his best time for 100 metres was 12.3 seconds, so even at 50 per cent of his top pace there was the capability to run at 6.6 minute miling. This was just slower than his best steady state running pace. Because the injury occurred mid-season and time away from running was ten days, it would be safe to test the effect of short interval steady state runs at approximately half volume. The unit of work was four repetitions of two minute runs with two minutes recovery. This caused no reaction to the muscle injury and so could be progressed to a point where aerobic fitness could be improved at a time when full speed and change of direction could not be achieved.

When the other components of phase two and three of rehabilitation are complemented by the player's clear understanding of the time scale required to regain tensile strength of tissue, physiological fitness, skill and coordination, then recurrence of the injury or the production of a related injury are less likely.

Player compliance with a rehabilitation programme will be improved if the time scale can be directed to a particular part of the season which has special significance for that player. Unless the player is aiming for the zenith of his career or is approaching its end, the long term view should be taken. In every case achievable intermediate functional goals must be set to maintain the player's compliance and motivation. These are even more important if prediction of the rate of recovery does not fit with the timescale of a major sporting event in the player's life. It is also important that external pressures from manager, coach, peer group, and family are not contradictory to the management of the injury.

\section{Injury prevention}

The very nature of contact sport makes it impossible to prevent all injury. Nevertheless, every effort should be made to avoid injury. During the game, technique is all important and the astute coach very quickly recognizes dangerous practices. Their skilled eye in game analysis and knowledge of the rules are essential for injury prevention during the game. Senior players can play the same role and their expertise should be used.

What the physiotherapist has to offer is more related to prevention of injury during training. Assessment of tissue reaction to particular work loads is particularly important. An example is included to illustrate the point.

A middle distance runner during the winter preparatory period has done the first strength 
endurance hill session on a Saturday. The next day one calf felt sore and tender. A slow recovery run was done on Sunday, and on Monday the session was a fast four mile road run. This produced a reaction at the musculotendinous region of the calf which took six weeks to recover with the accompanying loss of form. This could have been avoided by one or two days rest with modification of the next two day's training load. The mistake here was not necessarily one of training load, but of failing to identify the significance of the tissue response to a new training load. The identification of tissue responses which require work loads to be changed is an important role of the physiotherapist, who may thereby facilitate a return to full function.

Another aspect of injury prevention in training relates to the specific structure of training sessions. In rugby union this is particularly apparent during tours.

On tour, amateur players are in a position to train every day. For the coach this is an ideal opportunity to improve fitness and skill levels. The success of a tour is based on results, so the coaches' objectives can be understood. Unfortunately, a very dynamic approach can be counter-productive, as analysis of injuries from three Scottish rugby tours suggest (Table 2). (Definition of an injury: signs and symptoms of musculoskeletal origin which cause the player to miss training or playing the next day.)

Table 3 shows that the frequency of intrinsic injury, which includes overuse injuries, is greater than extrinsic injury and that intrinsic injury tends to occur more frequently in training. Table 4 indicates that injuries incurred in training take longer to resolve. This is probably due to the higher incidence of intrinsic injuries in training.

The frequency, density, volume, intensity and uneven progression of physical activity are all contributory factors to intrinsic injury. The message is clear if the number of injuries and time lost due to injury are to be reduced ${ }^{16}$.

When planning the structure of training and game preparation, the individual player must be considered. During the 1987 Rugby World Cup the incidence of injury in training was one every $2.9 \mathrm{~h}$

Table 2. Origin and frequency of musculoskeletal injuries on three Scottish tours

\begin{tabular}{lccc}
\hline & $\begin{array}{c}1981 \\
\text { (New Zealand) }\end{array}$ & $\begin{array}{c}1982 \\
\text { (Australia) }\end{array}$ & $\begin{array}{c}1987 \\
\text { (New Zealand) }\end{array}$ \\
\hline $\begin{array}{l}\text { Injuries sustained } \\
\text { during training }\end{array}$ & $4(25 \%)$ & $8(38 \%)$ & $9(45 \%)$ \\
$\begin{array}{l}\text { Injuries sustained } \\
\text { during game }\end{array}$ & $10(62 \%)$ & $10(47.6 \%)$ & $6(30 \%)$ \\
$\begin{array}{l}\text { Both } \\
\text { Other }\end{array}$ & $2(13 \%)$ & $2(9.5 \%)$ & $4(20 \%)$ \\
& $0(0 \%)$ & $1(4.9 \%)$ & $1(5 \%)$ \\
\hline
\end{tabular}

Incidence of injuries related

to time during:

\begin{tabular}{llll} 
Training & 1 per $11 \mathrm{~h}$ & 1 per $6.75 \mathrm{~h}$ & 1 per $2.9 \mathrm{~h}$ \\
Game & 1 per $1.06 \mathrm{~h}$ & 1 per $1.20 \mathrm{~h}$ & 1 per $0.86 \mathrm{~h}$ \\
\hline
\end{tabular}

compared with one every 6.75 and $11 \mathrm{~h}$ in 1982 and 1981 respectively. A possible explanation for the higher incidence was the relative experience of the players. The average age of the three touring parties was very similar but the average number of caps won was much higher in 1987. The relationship between experience at the top level and musculoskeletal injury is even clearer in Table 5 and illustrates just one aspect which should be considered when conditioning a team of individuals.

Coaches are under extreme pressure because their reputation is at stake. Ironically, their approach to conditioning can increase that pressure. This can only be changed if there is prospective and regular dialogue which includes player, coach, physiotherapist and doctor to ensure that the structure of conditioning programmes acknowledges the correlation between frequency, intensity, volume, density and injury ${ }^{17}$.

Table 3. Frequency of intrinsic and extrinsic musculoskeletal injuries on three Scottish tours

\begin{tabular}{lccc}
\hline & $\begin{array}{c}1981 \\
\text { (New Zealand) }\end{array}$ & $\begin{array}{c}1982 \\
\text { (Australia) }\end{array}$ & $\begin{array}{c}1987 \\
\text { (New Zealand) }\end{array}$ \\
\hline Extrinsic & & & \\
Training & 0 & 0 & 4 \\
Game & 5 & 8 & 3 \\
Total & $5(31 \%)$ & $8(38 \%)$ & $7(35 \%)$ \\
& & & \\
Intrinsic & & 8 & 5 \\
Training & 4 & 2 & 3 \\
Game & 5 & 2 & 4 \\
Both & 2 & 1 & 1 \\
Other & 0 & $13(62 \%)$ & $13(65 \%)$ \\
Total & $11(69 \%)$ & & \\
\hline
\end{tabular}

Table 4. Average training time (days) lost due to musculoskeletal injuries on three Scottish tours

\begin{tabular}{lccc}
\hline & $\begin{array}{c}1981 \\
\text { (New Zealand) }\end{array}$ & $\begin{array}{c}1982 \\
\text { (Australia) }\end{array}$ & $\begin{array}{c}1987 \\
\text { (New Zealand) }\end{array}$ \\
\hline Training & 5.8 & 6.0 & 4.6 \\
Game & 2.9 & 5.2 & 3.1 \\
\hline
\end{tabular}

Table 5. Average age and number of caps of those suffering muscle tears and overuse injuries on three Scottish tours

\begin{tabular}{lccc}
\hline & $\begin{array}{c}1981 \\
\text { (New Zealand) }\end{array}$ & $\begin{array}{c}1982 \\
\text { (Australia) }\end{array}$ & $\begin{array}{c}1987 \\
\text { (New Zealand) }\end{array}$ \\
\hline Age & $28.8(27)$ & $26.9(26.6)$ & $29.3(27.9)$ \\
Caps & $13.4(9.8)$ & $12.7(11)$ & $28.3(16.6)$ \\
\hline
\end{tabular}

Squad figures in brackets. 


\section{Conclusion}

The chartered physiotherapist can fulfil a variety of roles in conjunction with medical back up. Injury prevention is the most important. Prevention may be achieved if a support team is available to the players. The coach and physiotherapist are equally responsible for injury prevention in training. The coach is the prime mover in prevention of injury on the field through teaching of safe techniques. The administrators have a responsibility to involve and consult a support team and review the rules of the game to include the prevention of injury.

\section{References}

1 Shellock, F,.G. and Prentice, W.E. Warming-up and stretching for improved physical performance and prevention of sports related injuries Sports Med 1985, 2, 267-278

2 Ekstrand, J., Gillquist, J. and Liljedahl, S. Prevention of soccer injuries Am J Sports Med 1983, 11, 116-120

3 Vaes, P., DeBoeck, H., Handelberg, F. and Opdecam, $P$. Comparative radiological study of the influence of ankle strapping and taping on ankle stability J Orthop Sports Phys Ther 1985, 7, 110-114

4 McLean, D.A. Use of adhesive strapping in sport $\mathrm{Br}$ J Sports Med 1989, 23, 147-149

5 McLean, D.A. The use of cold and superficial heat in the treatment of soft tissue injuries $\mathrm{Br} J$ Sports Med $1989,23,53-54$

6 Wiktorsson-Moller, M., Oberg, B., Ekstrand, J. and Gilquist, J. Effects of warming up, massage, and stretching on range of motion and muscle strength in the lower extremity Am J Sports Med 1983, 11, 249-252

7 Jozsa, L. Fine structural study of human skeletal muscle injuries due to blunt trauma J Legal Med (Berlin) 1978, 82, 145-152

8 Bauer, W., Short, C.L. and Bennett, G.A. The manner of removal of proteins from normal joints $J$ Exp Med 1933, 57, 419-433

9 Kvist, M. and Jarvinen, M. Clinical, histochemical, and biomechanical features in repair of muscle and tendon injuries Int J Sports Med 1982, 16, 12-14

10 Nikolaou, P.K., MacDonald, B.L., Glisson, R.R., Seaber, A.V. and Garrett, W.E. Biomechanical histological evaluation of muscle after controlled strain injury Am J Sports Med 1987, 15, 9-14

11 Heisner, T.M., Weber, J., Sullivan, G., Clare, P. and Jacobs, R. Prophylaxis and management of hamstring muscle injuries in intercollegiate football players $A m J$ Sports Med 1984, 12, 388-390

12 Jamieson, R. Jamieson and Kay's Textbook of Surgical Physiology. (3rd Edition) Churchill Livingstone, Edinburgh, UK 1982

13 Julsrud, M.E. Osteitis pubis J Am Pediatric Med Assoc 1986, 76, 562-565

14 Booth, F.W. Time course of muscular atrophy during immobilisation of hind limbs of rats J Appl Physiol 1977, 43, 656-661

15 Harre, D. Principles of Sports Training. Sportverlag Berlin 1982

16 James, S. Injuries in runners Am J Sports Med 1978, 6, 40-50

17 Pollock, M.L. Effects of frequency and duration of training on attrition and incidence of injury Med Sci Sports 1977, 9, 31-36 